\title{
FLEXIBILIZANDO AS FRONTEIRAS ENTRE O CAMPO E A CIDADE: A PROXIMAÇÃO DOS MODOS DE VIDA RURAIS E CITADINOS ATRAVÉS DOS PADRÕES DE CONSUMO
}

Nayhara Freitas Martins Gomes ${ }^{1}$

\section{Resumo}

Este artigo teve por objetivo compreender como o padrão consumo compreendido pelas variáveis (acesso a eletrodomésticos, tecnologias de comunicação e informação e posse de meios de transporte) são influenciadas pelo nível de urbanização do município (percentual de domićlios em condição urbana). Utilizou-se como fonte de dados o Censo do ano de 2010 referentes ao estado de Minas Gerais e como método o GWR (GeographicallyWeightedRegression) por permitir estimar ospadrões relacionais tendo em conta sua variação espacial. Observou-se, em termos dos resultados, que há uma dependência entre padrão de consumo e nível de urbanização. Entretanto, pode-se identificar a ocorrência de municípios rurais com alto padrão de consumo, bem como, municípios essencialmente urbanos com baixo padrão de consumo. Estes resultados apresentam correspondência com a concepção teórica utilizada que conduziu o enquadramento analítico deste artigo ressaltando a dimensão expansiva dos modos de vida urbanos sobre os diferentes contextos sociais. Por fim, pode perceber que de fato, do ponto de vista material, há uma intensificação das relações entre o campo e a cidade por meio das transformações em seus modos de vida.

Palavras-chave:Modos de vida, consumo, Censo 2010, Minas Gerais.

1 Doutoranda em Geografia na Universidade Federal de Minas Gerais (UFMG)

Mestre em Extensão Rural na Universidade Federal de Viçosa (UFV)

Licenciada e Bacharela em Geografia (UFV)

nayhara_martins@yahoo.com.br 


\section{1- INTRODUÇÃO}

O objetivo deste artigo foi analisar as aproximações entre o modo de vida daqueles que vivem no campo e na cidade, no estado de Minas Gerais. Buscamos verificar, especificamente, como as variáveis referentes ao padrão de consumo de bens duráveis, acesso a eletrodomésticos, as tecnologias da informação e comunicação e meios de transporte se manifestam nos municípios em diferentes níveis de urbanização, de modo a observar as mudanças no modo de vida, via consumo das pessoas que ali vivem. $\mathrm{O}$ enquadramento teórico apresentado neste artigo, se constrói com base na concepção que interpreta os modos de vida rurais e urbanos como não sendo específicos a limites espaciais determinados.

Nessa perspectiva, entende-se que o campo e a cidade não podem ser utilizados como sinônimos de rural e urbano, pois, o campo não necessariamente precisa ser a base prática de manifestação do rural e, de forma semelhante, a cidade ser a base de manifestação do urbano. Deste modo, o urbano não se restringe somente à sociedade que mora na cidade.A distinção entre o rural e o urbano está muito mais vinculada à reprodução das relações sociais que a materialidade espacial, campo e cidade permite pensar no que diz respeito estritamente às manifestações do rural na cidade e do urbano no campo. Neste contexto, dentre as mais diversas dimensões de expressões urbanas que adentra no campo, destaca-se os hábitos de consumo. Segundo Candido (1997), o consumo assinala as mudanças nos modos de vida do caipira paulista face ao avanço do processo de urbanização dos bens de consumo antes produzidos a nível doméstico, os quais passam cada vez mais a serem substituídos por itens comprados fora da propriedade. É, então, neste contexto de metamorfoses sociais, econômicas e políticas que as discussões sobre as relações entre o campo e a cidade são, na contemporaneidade, de demasiada relevância, para dar conta de seus novos conteúdos e novas formas.

O artigo que ora se apresenta conta com materiais empíricos a partir dos microdados do Censo Demográfico do ano de 2010,acerca de variáveis que atuam como proxies paraos padrões de consumonos domicílios do estado de Minas Gerais. Na próxima seção, apresenta-se uma discussão teórica buscando enaltecer o estreitamento das relações entre o campo e a cidade via modos de vida, principalmente pela dimensão do consumo. $\mathrm{Na}$ sequência disto, os percursos metodológicos traçados no desenvolvimento deste estudo e em seguida, as discussões e análises dos dados empíricos utilizando o método GWR (GeographicallyWeightedRegression), a fim de perceber a influência da variável independente, nível de urbanização, em relação à variável dependente padrão de consumo. 
Desta forma, a contribuição deste artigo reside na tentativa de caracterizar a associação entrepadrões de consumo existentes no campo e na cidade indicando os aspectos existentes de ruralidades e urbanidades nestas porções espaciais.

\section{2- MARCO TEÓRICO}

\subsection{A proximidade entre o campo e a cidade na contemporaneidade.}

$\mathrm{Na}$ atualidade, o espaço geográfico vem assumindo uma nova organização territorial. As fronteiras espaciais estão cada vez mais articuladas com os fluxos globais e envolvidas por novos modelos de intercâmbio através de redes de circulação e comunicação ligadas por uma dinâmica espaço-temporal. Segundo Santos (1997), o espaço como fruto de relações sociais, como um constructo social, vem sofrendo um processo de metamorfose, (re) construindo novas fronteiras espaciais cada vez mais flexíveis face à conectividade entre o local e o global, de modo que os limites geográficos à escala mundial ficam atenuados.

A compreensão do rural e do urbano no contexto contemporâneo está vinculada ao seu par dialético: o campo e a cidade. E, para isto, é necessário distinguir com clareza os seus significados, como destaca Whitacker (2010, p. 191), que afirma ser tal distinção necessária porque a "cidade" e o "campo" se caracterizam por expressarem formas espaciais, enquanto "urbano" e "rural” possuem uma dimensão processual, são conteúdo e contingente. Campo e cidade são formas concretas, "materializam-se e compõem as paisagens produzidas pelo homem; 'urbano' e 'rural' são os conteúdos das práticas de cada sujeito, cada instituição, cada agente na sociedade" (BIAZZO, 2008, p. 144).

Além da vinculação dialética entre rural-urbano e campo-cidade, é necessário considerar que os avanços da ciência, da técnica e da informação se disseminam de forma desigual no espaço geográfico, seletivamente, tornando a dinâmica socioespacial mais complexa, dificultando a distinção entre o rural e o urbano. Embora no período contemporâneo as articulações entre campo e cidade se intensificaram, esses espaços continuam apresentando características que lhe são específicas, particulares, como fragmentos do espaço geográfico (totalidade).

A visão que predominou sobre os estudos do campo, o colocava como um espaço ligado ao setor primário (KAGEYAMA, 2008) enquanto a cidade estaria ligada a uma diversificada cadeia produtiva. Entretanto, essa concepção foi sendo ultrapassada, aos poucos, uma vez que o campo passou a se dedicar a atividades que não estavam apenas ligadas à agricultura. Diante do contexto de transformação do campo tanto na base 
produtiva quanto na organização social, a distinção entre rural e urbano tornou-se difícil, pois elementos de um modo de vida urbano passaram a ser incorporados no campo, mesclando-se aos modos de vida rurais, da mesma forma que os mesmos passaram a ser reproduzidos na cidade.

Após a Segunda Guerra Mundial, sobretudo, na Europa, novas atividades produtivas e de prestações de serviço foram se desenvolvendo, de forma crescente. No campo, as casas foram se equipando com tecnologias domésticas, tecnologias da informação e comunicação e meios de transporte, incorporando práticas de trabalho e de sociabilidade citadinas. As mudanças nas práticas e costumes que foram se instituindo nos modos de morar e de viver no campo, devido à proximidade com a cidade, permitiu a alguns segmentos sociais mais que outros, adotarem, nas sociedades rurais novos comportamentos e práticas, contribuindo, assim, para a penetração de um modo de vida urbano no campo.

As mudanças econômicas, demográficas e sociais vivenciadas na França, na década de 1960, foram os alicerces para o desenvolvimento de estudos sobre a sociedade rural realizados por Rambaud (1969). Para este autor, o campo e a cidade estavam envolvidos em uma dinâmica universal dada pelo processo de urbanização dos modos de vida. Essas formas de viver urbanas nasceram na cidade, mas ultrapassaram os seus limites e passaram a ser reproduzidas no campo. Os indivíduos que viviam nas sociedades rurais, ao julgar necessário a incorporação de elementos da cultura vinda das cidades, instauraram uma série de mudanças comportamentais e de práticas relativas à racionalidade econômica. A incorporação de um modo de vida urbano no campo teve no consumo um dos principais veículos de mudança. Conforme Rambaud (1969), a estética do consumo se destacaria por lançar a sociedade rural ao contato mais estreito com a cidade. O automóvel e as motocicletas foram alguns dos símbolos e instrumentos adequados para reduzir o deslocamento no espaço e no tempo.

Esta incorporação dos hábitos de consumo urbanos expressariam as escolhas seletivas feitas pelos rurais daquilo que consideravam mais relevante para si no ambiente urbano, construindo o que Rambaud (1973) denominou de "canevas", ou seja, uma escolha de elementos da cultura urbana para compor o seu modo de vida. O "canevas" se constituiria, em uma expressão do ideário relativo ao projeto de vida do sujeito. PlacideRambaud (1973) destacava tal processo como uma forma heterogênea e multifacetada de urbanização do campo. Determinados segmentos sociais, como os jovens e as mulheres, gradualmente, participam da vida da cidade e reproduzem os modos de vida 
e de consumo urbano. O autor utiliza as categorias de urbano e rural como modos de vida que passam a ser transformados a partir da relação entre o campo e a cidade. Estes espaços foram vistos pelo autor como espaços não antagônicos, mas relacionais. No campo, o processo de urbanização apontaria, assim, para a escolha de um modo de vida.

Tal como para Rambaud (1969) também Endlich (2010) conceitua urbano e rural como não estando restrito à cidade ou ao campo, respectivamente. O modo de vida urbano não se limitaria apenas à cidade, mas extrapolaria as suas fronteiras, chegando ao campo de acordo com as demandas dos diferentes segmentos dos que habitam este espaço. Para Lefebvre (2001), o urbano, ou a sociedade urbana, seria uma virtualidade, uma projeção que carregaria a constituição de uma sociedade planetária, uma totalidade que se modificaria, em ritmos heterogêneos e singulares. Ainda segundo o autor, a cidade e o campo teriam experimentado alterações no tempo. Em um primeiro momento, a diferenciação se deu em função da divisão do trabalho. Já quando houve a expansão da indústria, o campo foi absorvido pela cidade e houve a ampliação dos modos de vida urbanos, com a difusão de tecnologias, de símbolos urbanos e da troca de mercadorias. A noção de urbano passou a superar a concepção de divisão. A sociedade urbana se estendeu ao campo, sem suprimir, no entanto, o desenvolvimento das atividades agrícolas. Sendo assim, os conteúdos do campo se mesclaram com as formas urbanas.

Rua (2000) dá ênfase às particularidades e singularidades que marcam tanto o rural quanto o urbano tendo uma visão mais integradora a partir de uma abordagem territorial, ou seja, a partir das territorialidades em que o urbano e o rural se configuram. Segundo Rua (2000), a identidade do rural contemporâneo pode ser apreendida a partir da consideração de uma série de "mistos". A incorporação de "urbanidades", entendidas como a manifestação de elementos urbanos no campo, produz uma interação que dá lugar a territorialidades ímpares. Soto (2011) argumenta que, o rural deveria deixar de ser visto, como referência aos aspectos geográficos e passar a ser entendido a partir das relações sociais. Por isso, para Biazzo (2008), seria importante observar a existência de ruralidades e urbanidades, as quais expressariam as racionalidades, as construções simbólicas, as manifestações ou criações culturais concebidas, a partir de hábitos e costumes diferenciados localmente.

A abordagem da relação cidade-campo a partir das territorialidades advém do reconhecimento de que os atores sociais presentes nesses espaços vivenciam e produzem múltiplas territorialidades por meio das diferentes escalas de ação (local/regional/global). No mundo globalizado, as fronteiras entre o rural e o urbano são cada vez mais tênues, 
dada a intensidade das relações que se estabelecem entre eles, podendo os sujeitos sociais interagir não apenas com a escala local. Essa mobilidade e transitoriedade pelas diferentes escalas de ação são possibilitadas pelo processo de globalização, que integra os diversos lugares do planeta, mesmo os mais distantes. As diferentes escalas nas formas de ação marcam o surgimento de espaços dotados de uma hibridez e inovação, resultantes da interação entre o urbano e o rural.

Rua (2000) ressalta, no entanto, que mesmo o campo incorporando elementos do modo de vida urbano este preservaria especificidades, tornando-se um território híbrido, uma amálgama de particularidades onde os modos de vida rural e urbano interagiriam. Dessa forma, o campo, ao guardar especificidades, permitiria uma identidade social coletiva, a qual poderia ser vista como uma conexão do contexto local com o global, através da ação dos indivíduos. As identidades seriam pluralizadas, marcadas por novas formas de comportamentos. O processo de urbanização, nesse contexto, não implicaria na homogeneização dos espaços. Seguindo nesta compreensão da conectividade entre os espaços e os modos de vida, Biazzo (2008) e Hespanhol (2011), percebem o rural e o urbano como qualidades das relações sociais, sendo que o rural e o urbano poderiam conviver no mesmo local, em decorrência do tipo de práticas adotadas pelos sujeitos.

Nesse sentido, o campo e a cidade poderiam ser identificados como uma realidade material, enquanto que as respectivas categorias rural e urbano corresponderiam a uma realidade social produzida no espaço. Também Santos (1993) considera cidade e campo como formas no espaço e defende que urbano e rural evidenciariam o conteúdo social de tais formas. Assim, entendemos que na definição de rural e urbano há a necessidade de se considerar as dimensões sociais e culturais de cada espacialidade, uma vez que são elas que engendram significado às relações estabelecidas nos espaços. Lefebvre (2001, p. 49), clarifica esta discussão, ao afirmar que a cidade pode ser lida como uma morfologia material, uma realidade presente, imediata, um dado prático-sensível, arquitetônico. Já o urbano corresponderia à morfologia social, a uma realidade social composta de relações presentes e relações a serem concebidas, construídas ou reconstruídas pelo pensamento. Nesse sentido, as relações entre cidade e urbano são estreitas, já que é impossível para a vida urbana dispensar uma base prático-sensível, que se constitui em produto e condição da dinâmica social.

Um dos traços marcantes da ruralidade contemporânea é o crescente avanço da racionalização da vida rural. As atividades primárias ligadas à agricultura e à pecuária cedem espaço a uma maior diversificação produtiva com crescente diferenciação 
social e econômica. Endlich (2010) afirma que o Brasil é mais urbano do que se imagina, pois ao considerar os modos de vida dos indivíduos percebe-se uma forte influência urbana nas práticas e hábitos cotidianos hodiernos. Em suma, campo e cidade são compreendidos como espaços (formas) dotados de conteúdos (modos de vida), rurais e urbanos. Esses conteúdos, entretanto, podem extrapolar os seus espaços de origem e, portanto, qualquer definição que se apresente de forma estanque pode impossibilitar uma análise mais completa da realidade que, em si, é dotada de uma multiplicidade de sentidos. Dessa forma, ampliam-se as coexistências, as contradições e os conflitos entre diferentes temporalidades e espacialidades presentes no rural. Como destaca Marques (2003, p. 108), além dos diferentes conteúdos assumidos pelos espaços urbano e rural no tempo, a contemporaneidade também comporta o diverso. A lei do desenvolvimento desigual e combinado nos remete para diferenças de ritmo e intensidade com que as mudanças se processam no campo e na cidade e internamente a estes espaços.

Diante do exposto, endossamos a perspectiva de Rambaud (1973), de Wirth (1979), Candido (1997), Guerra (1993), Setubal (2005), Sorre (1958), Lefebvre (2001) e Brandao (2009) segundo a qual a força da cultura urbana é expansiva e age sobre a sociedade rural através da paulatina incorporação e reprodução de elementos urbanos, em formas e ritmos diferenciados, resultando este processo na diversificação da base produtiva e da organização social local. É importante perceber que o "modo de vida" envolve dimensões identitárias, práticas, hábitos e valores, os quais se reconfiguram mediante processos de interação entre o campo e a cidade. A concepção teórica adotada neste estudo se fundamenta na concepção de "modos de vida" como as condições materiais ou simbólicas que permeiam as esferas sociais, econômicas e culturais, referentes a um grupo e aos indivíduos que o compõe

Os modos de vida rural e urbano permite a percepção de que as formas materializadas no espaço decorrentes das práticas cotidianas incidem sobre a distinção entre os modos de vida rural e urbano. A aproximação entre a cidade e o campo vem gradualmente transformando os hábitos, os costumes, e a percepção de mundo das pessoas que vivem no campo. No entanto, essas mudanças ocorrem de maneira irregular, com graus e conteúdos diversificados. São transformações que se dão de forma heterogênea, de acordo com os interesses e a posição social dos atores, o que pode, segundo Rambaud (1973), não implicar em uma ruptura abrupta no tempo, nem no conjunto do sistema social. 


\section{3- PROCEDIMENTOS METODOLÓGICOS}

Este estudo utilizou uma abordagem quantitativa de coleta e análise dos dados. $\mathrm{O}$ levantamento dos dados foi realizado em cross-section, no ano de 2010, com dados do Censo Demográfico Brasileiro de 2010, coletados no sítio do Instituto Brasileiro de Geografia eEstatística (IBGE). Foram selecionados para pesquisatodos os domicílios do estado de Minas Gerais. Destaca-se como limitação deste estudo,o fato dele estar restrito a algumas variáveis relativas ao consumo de bens duráveis, não explorando em amplitude os aspectos constitutivos dos modos de vida. Ademais, de ter considerado apenas o ano de 2010 para a análise, o que inviabilizaria afirmações mais contundentes. Entretanto, os dados do Censo de 2010 relativos ao consumo servem como proxies dos modos de vida, que é um dos componentes dos modos de vida. Assim, em termos dos bens de consumo analisados considerou-se: variáveis relativas a posse de eletrodomésticos (rádio, televisão, máquina de lavar roupa e geladeira), de Tecnologias de Comunicação e Informação, as chamadas TICs (aparelho de celular, telefone fixo, computador e acesso à internet) e os meios de transporte (motocicleta e automóvel próprio).

Para montar o banco de dados, os dados foram sistematizados no software estatístico SPSS (StatisticalPackage for Social Sciences). Classificou-se os domicílios mineiros frente a posse dos bens de consumo duráveis em duas faixas, em função dos objetivos do estudo: possui ao menos três eletrodomésticos, duas tecnologias de comunicação e informação e um meio de transporte, bem como aqueles domicílios que não possuíam estes itens seguindo esta lógica. Com isto, chegou-se ao percentual de domicílios com padrão de consumo elevado.

Posteriormente, todos os municípios mineiros foram categorizados em três segmentos em função da situação das unidades domiciliares "rurais" e "urbanas": rural (aqueles municípios que possuem até $50 \%$ dos domićlios no campo); predominantemente urbano (municípios com até $84,4 \%$ dos domicílios na cidade) e essencialmente urbano (aqueles municípios que possuem acima de 84,5\% dos domicílios na cidade). Vale ressaltar, que essa proposta de tipologia, justifica-se em função da atual taxa de urbanização brasileira que em 2010, era 84,4\% (IBGE, 2010). Esta taxa traduz a percentagem de população que vive nas cidades em relação à população total do território.

Objetivando buscar a influência da variável independente, nível de urbanização (percentual de domicílios em condição urbana por município), em relação à variável dependente, padrão de consumo (percentual de domićlios com padrão de consumo de bens elevado - identificado pelas variáveis selecionadas) utilizou-se o método GWR 
(GeographicallyWeightedRegression) na tentativa de modelar o padrão de distribuição espacial desta relação.

Este método permite estimar parâmetros estatísticos considerando as coordenadas locais dos dados em análise, ou seja, tendo em conta a sua variação espacial (Foody, 2003; Fotheringham et al., 2002). O GWR consiste de uma ferramenta estatística que utiliza a relação entre duas ou mais variáveis tal que uma variável possa ser explicada (variável dependente) pela outra (variável explicativa independente). Matematicamente essa relação é dada pela função: $\mathrm{Y}=\mathrm{aX}+\mathrm{b}$, permitindo que parâmetros locais sejam estimados (Zhang et al., 2004).

O GWR fornece um modelo local da variável ou processo socioespacial ajustando uma equação de regressão para cada característica no conjunto de dados. Em suma, o modelo uma regressão a cada ponto observado, ponderando todas as demais observações como função da distância a este ponto, expresso pela equação: $\mathrm{Y}(\mathrm{s})=\beta(\mathrm{s}) \mathrm{X}+\varepsilon$, onde $\mathrm{Y}(\mathrm{s})$ é a variável que representa o processo no ponto espaço. Nota-se o ganho de adequabilidade do modelo de regressão geograficamente ponderada por partir do pressuposto que o espaço é heterogêneo ou não-estacionário e a relação entre as variáveis dependentes e independentes assume padrões mais ou menos regionalizados. Por fim, os resultados obtidos pelo GWR foram representados cartograficamente em ambiente ArcGIS 10.3.

\section{4- RESULTADOS E DISCUSSÕES}

Inicialmente, levantou-se a seguinte hipótese: o nível de urbanização do município (em relação a situação dos domicílios que o compõem) influencia em um maior padrão de consumo das pessoas que ali vivem. Desse modo, as tipologias criadas (Tabela 1) subsidiaram todas as análises afim de testar a validade da hipótese. Segundo a classificação proposta, 17,5\% dos municípios de Minas Gerais eram rurais, portanto, aqueles municípios que possuem até $50 \%$ dos domicílios no campo. Já os municípios com predominância urbana, ou seja, aqueles com até $84,4 \%$ dos domicílios na cidade representava $60,3 \%$. Enquanto os municípios que possuíam a urbanização dos seus domicílios acima de 84,5\%, os essencialmente urbanos foram traduzidos por $23,3 \%$. 
Tabela 1 - Nível de urbanização dos municípios de Minas Gerais.

\begin{tabular}{ccc}
\hline Categoria & Frequência & Percentagem \\
\hline Rural & 149 & 17,5 \\
Predominantemente urbano & 514 & 60,3 \\
Essencialmente urbano & 190 & 22,3 \\
\hline Total & 853 & 100,0
\end{tabular}

FONTE: IBGE, 2010 (Adaptado pela autora).

É importante ressaltar que para o IBGE, a classificação da situação do domicilio é urbana ou rural, segue a área de localização do domicílio. Sendo assim, os domicílios de situação urbana são aqueles localizados nas áreas urbanas, que são as áreas internas ao perímetro urbano de uma cidade ou vila, definido por Lei Municipal. Já a área rural é a localidade situada em área legalmente definida como rural, onde existam unidades domiciliares que conformem um conjunto de edificações adjacentes $(50 \mathrm{~m}$ ou menos de distância entre si) com características de permanência.Em consonância com a literatura utilizada, a categoria "campo" adotada neste estudo engloba os domicílios classificados pelo IBGE em áreas rurais, já a categoria "cidade" considera os domicílios em áreas urbanas. Na figura 1 subsequente, observa-se uma maior concentração de municípios classificados como "rurais" na porção mais ao norte - nordeste do estado, bem como a leste. 
Figura 1: Classificação dos municípios mineiros segundo o nível de urbanização.

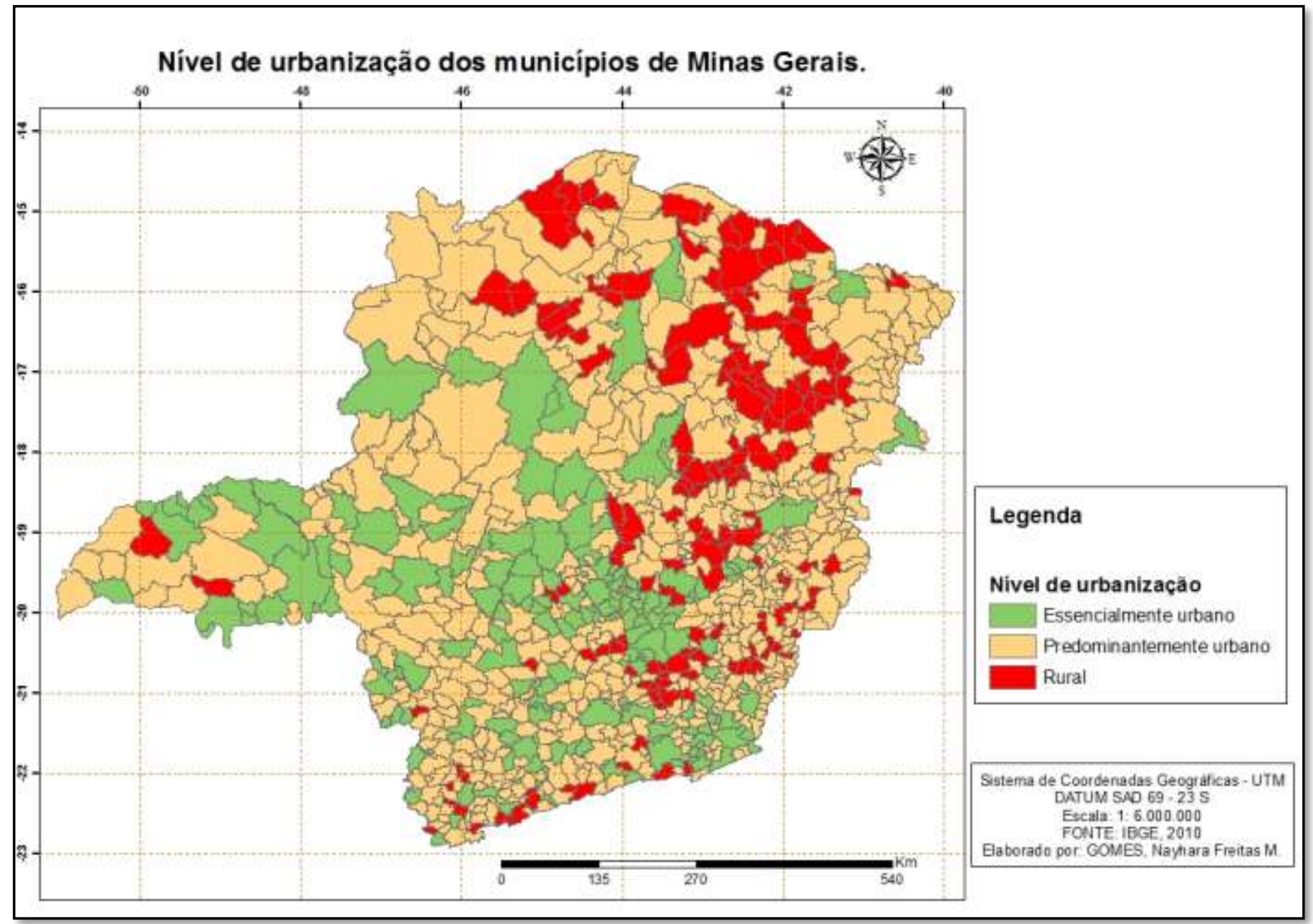

Em seguida, executou-se o método GWR, que ajusta um modelo de regressão para cada ponto no conjunto de dados, em vez de uma única área de regressão para o estudo inteiro. Basicamente, ele usa um kernel (também chamado de janela ou largura de banda) que se move sobre a área de estudo e procura ajustar os melhores resultados para cada subárea vizinha. Como resultado, cada ponto na região geográfica analisada tem seu próprio conjunto de coeficientes e isto permite que o modelo produza um valor de R2 individual para cada local, uma espécie de medida de sucesso do ajuste. Quanto mais próximos forem os valores deste coeficiente estiver de 1, mais ajustado está o modelo, enquanto que quanto mais próximo de 0 , pior este ajuste.Ao mapear esta distribuição geográfica dos resultados da aplicação do método GWR utilizando o algoritmo R2 Local, pode se observar como a relação entre as variáveis dependente e independente se comportaram espacialmente (Figura 2).

Figura 2: Método GWR utilizando o algoritmo R2 Local entre as variavéis consumo e urbanização. 


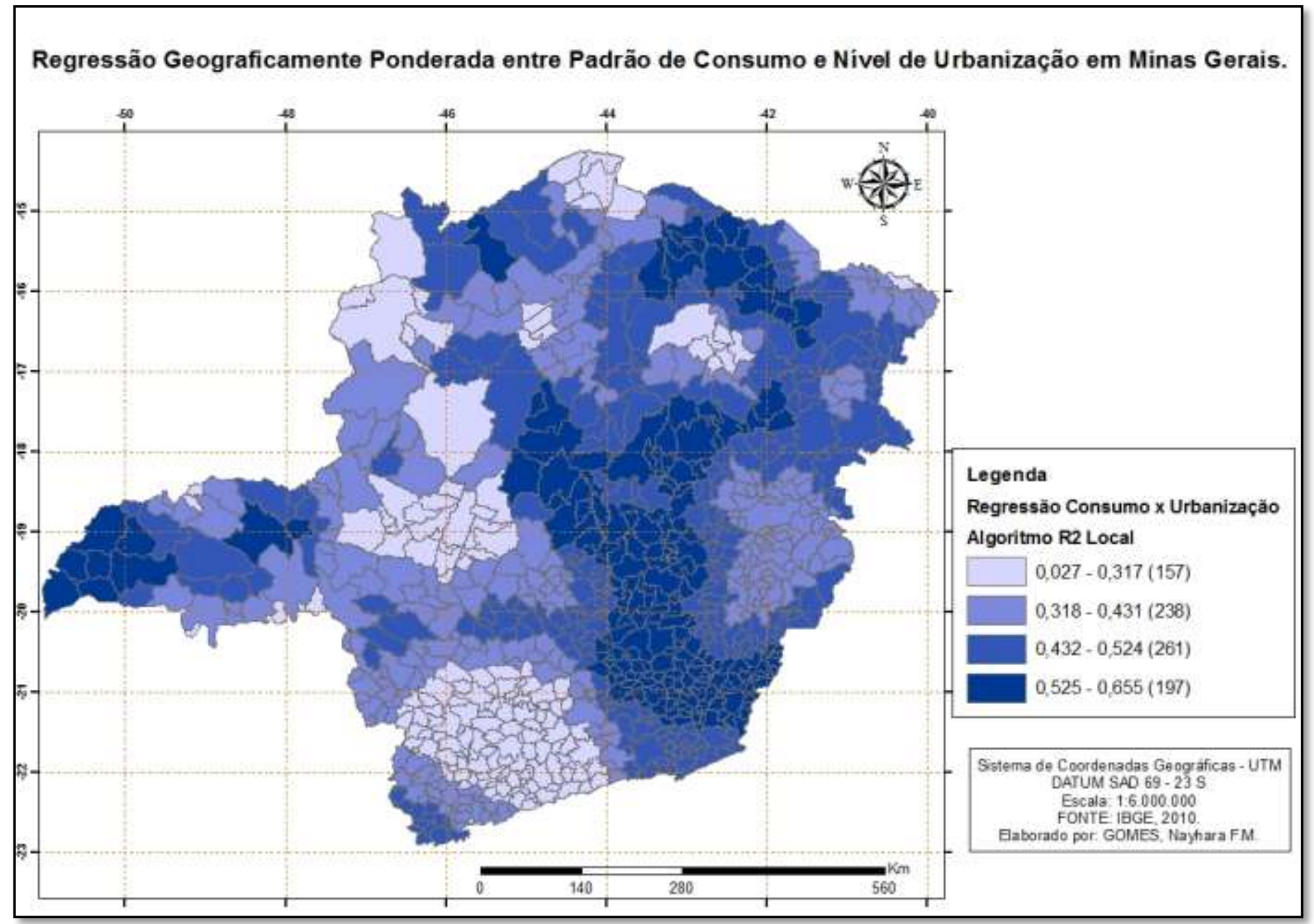

Pode-se realizar uma análise visual onde a dependência é estatisticamente significativo entre padrão de consumo e nível de urbanização.De maneira geral, as regiões apresentadas na cor mais escura (valores mais altos de R2) correspondem a um melhor ajustamento do modelo, ou seja, há um elevado padrão de consumo relacionado a um maior nível de urbanização, como ocorre em algumas porções das mesorregiões Central de Minas e Metropolitana, Zona da Mata, Jequitinhonha, no extremo do Triângulo Mineiro e Norte de Minas.Em contrapartida, em tons mais claros de azul (valores mais baixos), observa-seum pior ajuste do modelo, relações mais fracas, como emporções da mesorregião Sul/Sudoeste, Alto Paranaíba e Noroeste do estado.

É inegável a dependência espacial entre as variáveis testadas. Contudo, percebe-se algumas discrepâncias no que diz respeito aos municípios classificados como essencialmente urbanos e que apresentam baixos padrões de consumo, bem como ocorre exatamente o contrário em municípios tidos como rurais e com altos padrões de consumo. Estas particularidades, serão tratadas adiante. Entretanto, este fato é um importante indicativo de que o campo e a cidade estão envolvidos em uma dinâmica de aproximação Cadernos do Leste Artigos Cientificos 
dos seus modos de vida. Segundo Rambaud (1973), as formas urbanas de se viver nasceram na cidade, mas ultrapassaram os seus limites e passaram a ser reproduzidos no campo. Para o autor, os rurais "incorporariam" modos de vida urbanos em suas relações, através principalmente da aquisição de bens de consumo e de serviço que chegam ao campo. Portanto, estes dados realçam o aporte teórico utilizado neste texto, por evidenciar o nível das transformações observadas nos modos de vida dos rurais, nomeadamente, aquelas relativas às mudanças em termos do acesso a bens de consumo, às tecnologias da informação e da comunicação e posse de meios de transporte.

O modelo de GWR também produz outros resultados, como os resíduos padronizados. A estatística dos resíduos padronizados indica a soma dos quadrados dos resíduos no modelo (o resíduo é a diferença entre um valor y observado e seu valor estimado retornado pelo modelo GWR). Quanto menor esta medida, melhor. Estes representam nada mais que, a quantidade de variabilidade que permanece sem explicação pelo modelo (ou seja, a variabilidade sobre a variável dependente não explicada pelas variáveis independentes). Desse modo, a figura 3 indica os resíduos padronizados para a regressão entre consumo e urbanização.

Ao permutar para este algoritmo, a influência do consumo sobre a os diferentes tipos de municípios no que diz respeito ao seu nível de urbanização, demonstra que há uma dispersão geográfica desta relação. Em relação aos valores de resíduos padronizados, percebe-se que estes foram negativos e muito baixos, significando, portanto, que os resíduos são menores do que deveriam ser. Observa-se que não há uma nítida regionalização, tornando-se mais dificultosa a análise de agrupamentos. 
Figura 3: Método GWR utilizando o algoritmo Resíduo Padronizado entre as variavéis consumo e urbanização

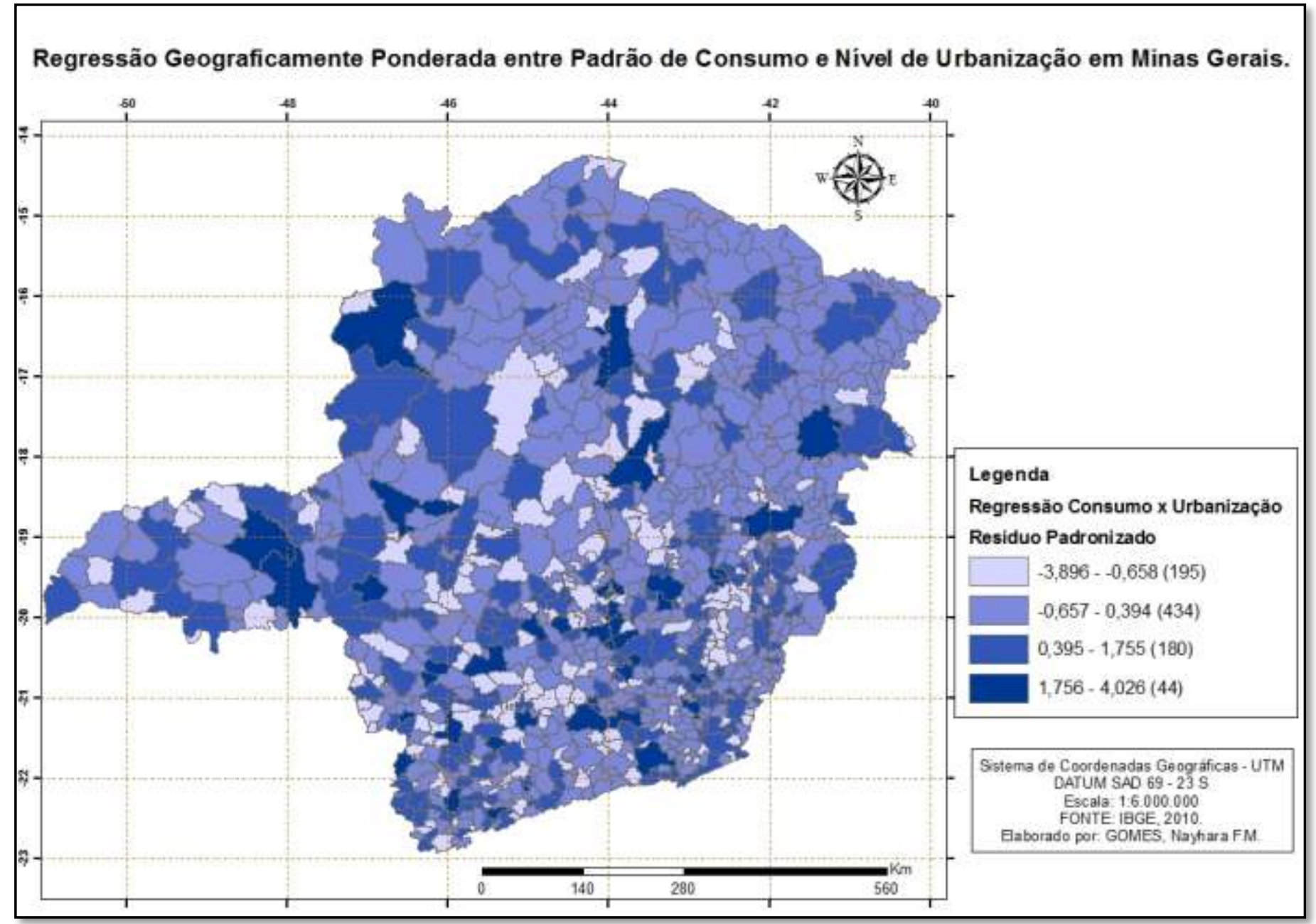

Diante dos altos valores dos resíduos padronizados, percebe-se que a relação entre as variáveis testadas têm grande variação espacial, mas chegou-se a algumas considerações importantessobre o território mineiro. Há municípios onde há a predominância de seus domicílios no espaço citadino, ou seja, são municípios essencialmente urbanos conforme a classificação proposta. Contudo, o padrão de consumo demonstra-se baixo. Este dado revela que não necessariamente estar na cidade, significa ter acesso a um modo de vida urbano do ponto de vista material, via padrão de consumo. Alguns casos na mesorregião do Triângulo Mineiro e Alto Paranaíba, como Patrocínio, Patos de Minas, Conquista, São Gotardo, Fronteira, entre outros,Central de Minas como Abaeté, Cedro do Abaeté, etc., Sul/Sudoeste, como Três Corações, Três Pontas, Varginha e São de Vicente de Minas são exemplos desta ocorrência.

Os resíduos padronizados também permitiu perceber que há municípios categorizados como rurais e que apresentam alto padrão de consumo, como na Cadernos do Leste Artigos Cientificos 
mesorregião do Norte de Minas, alguns casos como o deMontezuma, Santo Antônio do Retiro e Rio Pardo de Minas. No Jequitinhonha, Comercinho, Santa Cruz de Salinas eetc, na mesorregião Metropolitana, Ferros, Taquaraçu de Minas, Santana do Pirapema, São Gonçalo do Rio Abaixo e etc., no Vale do Rio Doce, Antônio Dias, na Central de Minas, Presidente Juscelino, no Triângulo e Alto Paranaíba, Gurinhatã, Itaipé no Vale do Mucuri, Senhora dos Remédios nos Campos das Vertentes e na Zona da Mata, alguns casos como ode Piranga, Araponga, Ervália, Canaã, Fervedouro, dentre outros.

Portanto, confrontando os dados disponibilizados com a teoria,podemos observar que os municípios tidos como ruraisnão necessariamente evidenciam uma menor penetração dos padrões de consumo no campo. Ao contrário, foi possível perceber que municípios tidos como essencialmente urbanos apresentaram padrões de consumo menores. Estes dados confirmam pesquisas que remetem o campo como um espaço que vem paulatinamente incorporando modos de vida urbanos. As pessoas que nele vivem buscam novas tecnologias, equipamentos para a casa e meios de transporte. Ou seja, no que tange a padrões de consumo, pode-se dizer que são pouco significativas as diferenças entre o campo e a cidade tal como aponta Braga et al (2014), Fiuza et al (2012) e Nascimento et al (2013), pois eles são itens presentes tanto no campo como na cidade.Assim, nos municípios estudados, no que diz respeito aos modos de consumo, aponta-se para um modo de vida urbano que vem se estendendo sobre o campo. Logo, denota-se uma aproximação entre os modos de vida rurais e urbanos que progressivamente vem atenuando as fronteiras entre estes espaços.

Assim, pode-se afirmar que modo de vida urbano está presente tanto no campo como na cidade, quando se observa esta dimensão material do modo de vida tratada neste estudo. Sem dúvida, algumas variáveis referentes ao padrão de consumo, demonstram vantagem em relação ao seu espaço de origem. Por exemplo, o acesso à internet, certamente reforça o fato de que esta tecnologia aparece primeiro na cidade, logo tem uma vantagem sobre este espaço, e só mais tarde este serviço alcança o campo.Segundo Bastos (2014), o acesso a esta tecnologia de informação ainda é um desafio no campo brasileiro, mesmo nas regiões mais desenvolvidas.

\section{5- CONSIDERAÇÕES FINAIS}

Os dados empíricos relativos aos modos de vida revelados através dos padrões de consumo apresentados no Censo de 2010 apontaram para uma aproximação entre os modos de se viver no campo e na cidade. Embora os municípios mais urbanizados tenham Cadernos do Leste 
apresentado maior tendência para um modo de vida urbano, do que o campo, há municípios rurais que revelaram um modo de vida mais urbano.Verificou-se que o modo de vida urbano vem, paulatinamente, ultrapassando os limites espaciais da cidade e sendo incorporados e reproduzidos no campo, principalmente pela via do consumo como expressa as variáveis referentes ao acesso à bens de origem urbana.

Neste sentido, reporta-se a contribuição social e científica desta investigação, por produzir informações que apontam a necessidade de repensar as políticas públicas direcionadas ao campo, que devem perceber que o campo e a cidade estão cada vez mais integrados. Além de compreender que o campo vem se constituindo em uma realidade diversa quanto suas relações e processos sociais.É imprescindível evidenciar os ganhos que se tem na percepção das transformações socialmente vividas, ao se diferenciar o espaço, em termos de forma (campo e cidade), dos modos de vida, considerando-os como conteúdo (rural e urbano). Perceber o estreitamento das relações entre os espaços e mais ainda quanto seus modos de vida é possibilitar enxergar as dimensões em que a cidade e o campo apresentam-se mais ruralizados ou urbanizados.

Todavia, reconhece-se que este tipo de análise traz vieses generalistas, os quais precisam ser ressaltados.As similitudes e dissonâncias merecem ainda ser tratadas de forma mais detalhada. Contudo, o estudo também traz também a possibilidade de apontar as dimensões em que os assentamentos humanos no campo e na cidade vêm se transformando. Por fim, destaca-se que os dados apresentados neste estudo apontaram para uma mudança no modo de vida rural, que no passado era voltado para sua autosustentação e hoje, com a monetarização, através do recebimento do salário, da aposentadoria e de outros benefícios, como o Bolsa Família, introduz no modo de vida rural a previsibilidade frente ao futuro. O consumo voltado para a melhoria da casa como eletrodomésticos, tecnologias da informação e comunicação e o acesso a meios de transportem se constituem em uma das facetas mais evidentes nas mudanças do seu modo de vida.

\section{REFERÊNCIAS BIBLIOGRÁFICAS}

BIAZZO, P. P. Campo e rural, cidade e urbano: distinções necessárias para umaperspectiva crítica em Geografia Agrária. In: Anais do IV Encontro Nacional de Grupos de Pesquisa ENGRUP. São Paulo, p. 132 - 150, 2008.

BRAGA, G. B.; FIÚZA, A. L. DE C.; PINTO, N. M. DE A. Os padrões de consumo no campo: o modo de vida dos rurais brasileiros. EstudiosRurales, v. 1, n. 6, p. 64-80, 2014. 
BRANDÃO, C. R. "No rancho fundo": espaços e tempos no mundo rural. Uberlândia: EDUFU, 2009. 244p.

CANDIDO, Antônio. Os parceiros do Rio Bonito: estudo sobre o caipira paulista e a transformação dos seus modos de vida. São Paulo, 8ª Ed, Ed 34, 1997.

ENDLICH, Ângela M. Perspectivas sobre o urbano e o rural. IN: Sposito, M.E.B. WHITACKER, A.M. (org.). Cidade e campo: relações e Contribuições entre urbano e rural. São Paulo: Editora Expressão popular, 2010, 11-31p.

FIÚZA, A. L. D. C.; PINTO, N. M. D. A. The contribuition of conceptual distinciction between "field" and "rural" and "city" and "urban" for researchers of rural sociology. XIII World Congress of Rural Sociology. July 29 to August 4. Lisboa 2012.

Foody, G.M. Geographicweighting as a furtherrefinementtoregressionmodeling: Anexamplefocusedonthe NDVI-rainfallrelationship. Remote Sensing of Environment, v. 88, p. 283-293, 2003.

Fotheringham, A. S., Brunsdon, C. \& Charlton, M. GeographicallyWeightedRegression: theanalysis of spatiallyvaryingrelationships. Editora John Wiley\& Sons Inc. England, 2002.

GUERRA, I. Modos de vida: novos percursos e novos conceitos. Sociologia - Problemas ePráticas, p. 59-74, 1993.

HESPANHOL, R. A. de M. Relações Cidade-Campo e Urbano-Rural: Contribuição para a análise geográfica do Projeto Cinturão Verde de Ilha Solteira, São Paulo e para o Programa Vilas Rurais em Lerroville, Paraná, Brasil. Revista GEOATOS, FCT/UNESP, Campus Presidente Prudente, 2011.

KAGEYAMA, Â. Desenvolvimento rural. Conceitos e aplicação ao Caso Brasileiro. Porto Alegre: Editora da UFRGS, 2008.

LEFEBVRE, Henri. A revolução urbana. Belo Horizonte: UFMG, 2001.

NASCIMENTO, P. F. DO et al. Variáveis evidenciadoras dos processos de transformação do campo: o caso do Espírito Santo - Brasil. Mundo Agrario, v. 13, n. 26, 2013.

RAMBAUD, Placide. SociétéRurale et Urbanisation. $1^{\text {a }}$ ed. Paris: Ed. duSeuil, 1969. . SociétéRurale et Urbanisation. 2ª ed. Paris: Ed. duSeuil, 1973.

RUA, João. Urbanização rural ou novas ruralidades? In: ENCONTRO NACIONAL DE GEOGRAFIA AGRÁRIA. 15. Goiânia, Comunicações... Goiânia: UFG, 2000 (a). p.418420.

SANTOS, M. Metamorfoses do espaço habitado. São Paulo: Hucitec, 1997.

SETUBAL, M. A. Vivências caipiras: pluralidade cultural e diferentes temporalidades na terra paulista. São Paulo: CENPEC, 2005.144p. 
SOTO, Willian Héctor Gómes. A crise da sociologia rural no Brasil e suas tradições teóricas. 2011. Disponível em: Acesso em: 07 Dezembro 2014.

WIRTH, L. O urbanismo como modo de vida. VELHO, O. G. O. Fenômeno urbano. 4a ed. Rio de Janeiro: Zahar editores, 1979.

Zhang, L., Bi, H., Cheng, P. \& Davis, C. J. Modelingspatialvariation in treediameterheightrelationships. Forest Ecology and Management, n.189, p. 317-329, 2004. 